\title{
INCLUSÃO NO ENSINO DE FÍSICA: CARACTERIZANDO DESAFIOS A PARTIR DE UMA ANÁLISE DE ARTIGOS DA SCIELO
}

\author{
INCLUSION IN PHYSICS TEACHING: CHARACTERIZING CHALLENGES FROM AN \\ ANALYSIS OF SCIELO ARTICLES
}

\author{
Heloisa Fernanda Francisco Batista ${ }^{1}$, Sandro Rogério Vargas Ustra ${ }^{2}$
}

Recebido: fevereiro/2021 Aprovado: maio/2021

\begin{abstract}
Resumo: $\mathrm{A}$ inclusão de estudantes público-alvo da Educação Especial (PAEE), em ambientes regulares de ensino, tem ocorrido de forma gradual, fomentada pela consolidação de um marco legal, dando-lhes voz e o direito de convívio em sociedade. As especificidades da aprendizagem desses estudantes têm representado um desafio para os professores e pesquisadores, especialmente no ensino de Ciências. Com o intuito de compor um quadro das pesquisas sobre o tema, foi realizado um levantamento na plataforma SciELO a partir dos termos: inclusão, educação inclusiva, necessidades educacionais especiais, ensino de Ciências, ensino de Física, formação de professores e deficiência visual. Foi possível apreciar a produção que aborda essa temática, pontuar as principais dificuldades no processo de inclusão de estudantes PAEE em turmas regulares e vislumbrar como as instituições de ensino superior têm buscado preparar o futuro docente para desenvolver atividades inclusivas, situando a necessidade de diálogo entre o professor de Física e o professor de Apoio. Acredita-se que este trabalho possa servir como ponto de partida para novas pesquisas, além de auxiliar na delimitação de novos temas de investigação. Palavras-chave: Inclusão, Formação de professores, Ensino de Física.
\end{abstract}

\begin{abstract}
The inclusion of public students of special education (PSSE), in regular teaching environments, has occurred gradually, fostered by the consolidation of a legal framework, giving voice to these students and the right to social life in society. The specificities of the learning of these students have represented a challenge for teachers and researchers, especially in science teaching. In order to compose a picture of research on the subject, a survey was conducted on the SCIELO platform based on the terms: inclusion, inclusive education, special educational needs, science teaching, physical education, teacher training and visual impairment. It was possible to evaluate the production that addresses this theme, to point out the main difficulties in the process of inclusion of PSSE students in regular classes and to glimpse how higher education institutions have sought to prepare the future teacher to develop inclusive activities, situating the need for dialogue between the physics teacher and the support teacher. It is believed that this work can serve as a starting point for new research, besides assisting in the delimitation of new research themes.
\end{abstract}

Keywords: Inclusion, Teacher training, Physics teaching.

\section{Introdução}

O número de estudantes público-alvo da Educação Especial (PAEE - O Decreto no 7.611, de 17 de novembro de 2011, considera público-alvo da Educação Especial as pessoas com

https://orcid.org/0000-0002-8437-7352 - Mestre em Educação pela Universidade Federal de Uberlândia (UFU). Doutoranda em Educação na Universidade Federal de Uberlândia (UFU), Uberlândia, Minas Gerais, Brasil. Avenida João Naves de Ávila, 2121, Bloco 1G, Santa Mônica, CEP 38408-100, Uberlândia, Minas Gerais, Brasil. E-mail: heloisa.f.batista@gmail.com

2 (iD https://orcid.org/0000-0003-3686-8664 - Doutor em Educação pela Universidade de São Paulo (USP). Docente na Universidade Federal de Uberlândia (UFU), Uberlândia, Minas Gerais, Brasil. Avenida João Naves de Ávila, 2121, Bloco 1G, Santa Mônica, CEP 38408-100, Uberlândia, Minas Gerais, Brasil. E-mail: srvustra@ufu.br 
deficiência, com Transtornos Globais do Desenvolvimento e com altas habilidades e/ou superdotação), matriculados em turmas de ensino regular, desde os Anos Iniciais do Ensino Fundamental ao Ensino Superior, vem aumentando gradativamente nos últimos anos. Vários movimentos ocorreram com o intuito de dar voz a esse público na sociedade (ONU, 1949, 1994; UNESCO, 1990; BRASIL, 2001, 2008, 2009, 2015), principalmente após a implementação de leis e decretos em nível nacional.

Além disso, vários documentos foram elaborados a partir de reuniões entre vários países e órgãos mundiais, como a Organização das Nações Unidas (ONU) e a Organização das Nações Unidas para a Educação, Ciência e Cultura (UNESCO). No âmbito educacional, isso possibilitou um aumento significativo no número de estudantes PAEE matriculados em turmas de ensino regular, desde os anos iniciais de alfabetização até o Ensino Superior.

Assim, foram construídas diretrizes que buscam auxiliar instituições escolares das esferas federal, estadual e municipal a respeito do processo de inclusão desse público nos ambientes escolares (BATISTA, 2017). Visando fortalecer o desenvolvimento integral desses estudantes e uma efetiva aproximação entre professores da Educação Especial e professores regentes de aulas, deve ser ofertado o Atendimento Educacional Especializado (AEE), em horários alternativos, com professores capacitados, com o intuito de complementar ou suplementar a formação do estudante, não dispensando o professor da sala de aula regular (BRASIL, 2008).

Segundo dados do Instituto Nacional de Estudos e Pesquisas Educacionais Anísio Teixeira (BRASIL, 2020), em 2019 havia em torno de 1,2 milhão de matrículas de estudantes PAEE em classes comuns e/ou escolas exclusivas em 2019, apresentando um aumento de $34,4 \% \mathrm{com}$ relação ao Censo de 2015. Nesse período, houve um aumento de 91,7\% no número de matrículas de estudantes PAEE no Ensino Médio, com um aumento significativo no número de matrículas nas escolas regulares de estudantes entre 4 e 17 anos, de 88,4\% em 2015 para 92,8\% em 2019.

É crescente o número de pesquisas voltadas à inclusão de estudantes PAEE em ambientes escolares e na sociedade como um todo, principalmente em relação à preparação dos professores para atender esses novos alunos e aos seus papéis diante do processo geral de inclusão (SILVA NETO et al., 2018; ANTUNES; ROCHA, 2017; RECH; AVILA, 2016; SILVA; ARRUDA, 2014). Nesse cenário, diversos pesquisadores buscam refletir sobre a prática adotada para 0 ensino dos conteúdos escolares de forma que possam contribuir significativamente no cotidiano dos estudantes, visando torná-los cidadãos conscientes, ativos e críticos na sociedade (FARIA et al., 2018; VOOS; FERREIRA, 2018). Também há uma preocupação com a preparação do futuro docente para atender às turmas compostas por estudantes com diversas especificidades em termos de aprendizagem, sendo ou não PAEE (TORRES; MENDES, 2019a, 2019b; CARMO et al., 2018).

Neste trabalho, apresentamos resultados de um levantamento bibliográfico de artigos, publicados na plataforma SciELO, relacionados ao processo de inclusão de estudantes PAEE, à formação de professores e ao ensino de Física para estudantes com deficiência visual. Nosso intuito era compor um quadro das pesquisas sobre a temática, a partir das produções bibliográficas. 
A análise dos artigos selecionados fundamentou-se nos principais aspectos relacionados ao foco das pesquisas, ano de publicação, periódico de publicação, metodologia, estratégia de análise de dados e principais resultados obtidos. Assim, foi possível compor um panorama onde se destacam características importantes quanto à percepção da diversidade do ambiente escolar, aproximação entre o Ensino Superior e a Educação Básica e oferta de formação iniciada e/ou continuada.

\section{0 conceito de inclusão}

A deficiência foi entendida de formas distintas de acordo com o período histórico que se tem registro até a atual configuração que busca incluir este público na sociedade como indivíduo ativo e participante. Devido à necessidade de incluir a pessoa com deficiência na sociedade como indivíduo ativo e participante, durante os últimos anos, houve uma preocupação em diferenciar e compreender os distintos processos de inserção, conforme ilustrado na Figura 1.

Figura 1 - Processos de inclusão da pessoa com deficiência na sociedade.

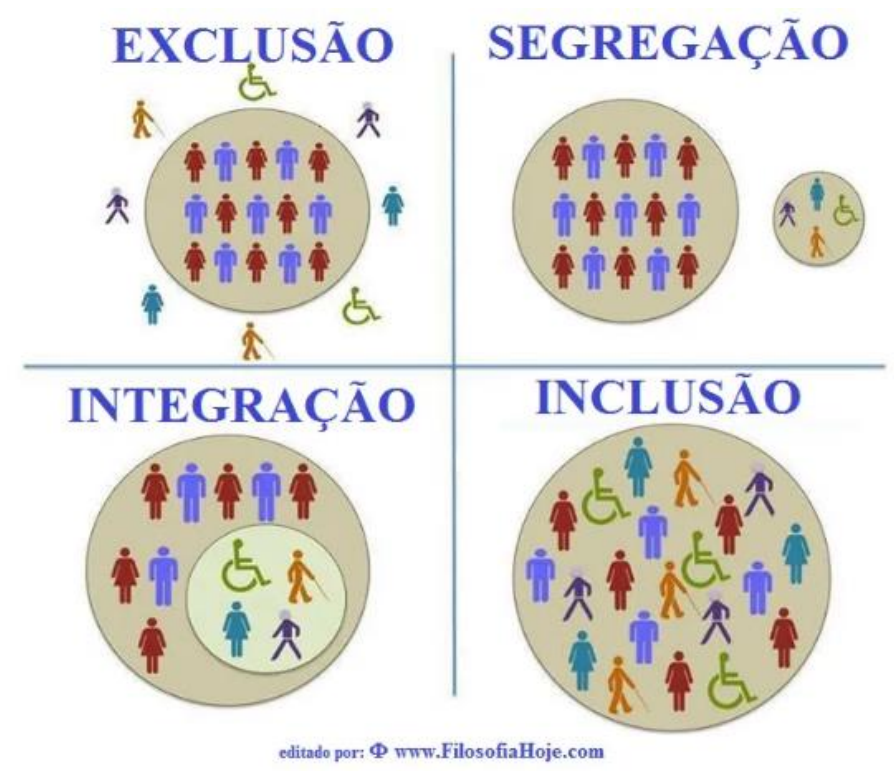

(Fonte: GOULART, 2014)

Na Idade Média, essa população era excluída da sociedade (processo de exclusão) e, dependendo do período histórico analisado, eram vistas somente como fonte de atrasos e despesas. Em diversos momentos, eram sacrificadas ou eram vistas, pelo dogma religioso, como sendo uma manifestação divina. Posteriormente, no século XIX e primeira metade do século XX, foi iniciado o processo de segregação, em que a pessoa com deficiência era encaminhada para centros específicos que ofertassem cuidados básicos, livrando a família dessas obrigações, como asilos, casas de adoção ou centros próprios para cuidados da pessoa deficiência (SANTOS; BARBOSA, 2016; SILVA, 2009).

Em 1948, foi promulgada a Declaração dos Direitos do Homem e dos Direitos da Criança, que buscou exprimir os anseios de inclusão, com relação à atenção fornecida ao público com deficiência. A partir do movimento realizado pelos centros de atenção específica, a sociedade começou a perceber a desumanização e a falta de qualidade no serviço prestado à pessoa com 
deficiência, além do alto custo e da grande lista de espera. Nesse período, tendo como objetivo a normalização da pessoa com deficiência, foi proposto o processo de integração, em que o indivíduo deveria se adequar à sociedade. Dessa forma, aquele que não conseguisse se adequar seria instruído, com sua família, a frequentar ambientes específicos, em que houvesse profissionais que suprissem suas necessidades (SILVA, 2009).

Distintos documentos legais, nacionais e internacionais, foram elaborados com a finalidade de proporcionar à pessoa com deficiência a participação na sociedade como indivíduo autônomo. No que se refere ao processo educacional, diversos decretos, estatutos e leis foram concebidos para tornar o ambiente escolar inclusivo, respeitando as especificidades dos indivíduos, dentre eles, pode-se citar o Estatuto da Criança e do Adolescente (ECA), a Lei de Diretrizes e Bases da Educação Nacional (LDBEN), a Política Nacional de Educação Especial na perspectiva da Educação Inclusiva, o Plano Nacional de Educação (PNE) 2014 - 2024 e a Lei Brasileira de Inclusão (BRASIL, 1990, 1996, 2008, 2014, 2015).

Após inúmeros estudos, debates e modificações no marco legal, tem-se buscado promover a plena inclusão da pessoa com deficiência na sociedade. Para que tal inclusão ocorra, é necessário que a sociedade se esforce para compreender e respeitar as especificidades desses indivíduos, ou seja, a pessoa com deficiência deve ser vista além de seu quadro, respeitada e aceita como participante da sociedade (GLAT, 2018; MANTOAN, 2015; SILVA, 2009).

Para que a inclusão se torne efetiva, três princípios devem ser observados: presença do estudante com deficiência no ambiente escolar regular, adaptação do ambiente escolar para que possa recepcionar os estudantes, independentemente de suas particularidades, e organização de meios para que o estudante com deficiência possa ser incluído na sala de aula regular (SASSAKI, 1999). Uma forma de avaliar o processo de inclusão em escolas regulares é através do acompanhamento da participação efetiva do estudante nas aulas e nas atividades escolares como um todo. Esta participação pode ser alcançada com o desenvolvimento de atividades elaboradas com o intuito de propiciar ao estudante uma atuação ativa e independente (CAMARGO, 2010). Porém, para que professor construa uma didática inclusiva é necessário que se afaste dos modelos tradicionais (CAMARGO; NARDI, 2008).

Em uma educação para a diversidade, o ambiente escolar deve contar com transformações no Projeto Político Pedagógico, na estrutura curricular, nas práticas pedagógicas, no processo avaliativo, nas estruturas arquitetônicas, dentre outros. Além disso, torna-se fundamental promover uma transformação nas relações interpessoais entre todos os membros da comunidade escolar (FRANZIN; ZWAN; CALLEGARO, 2020; GLAT, 2018).

A escola inclusiva requer uma transformação do ponto de vista educacional, pois ela engloba não só estudantes com deficiência, mas todos, observando as particularidades e carências de grupos que retratam a variedade humana que há em uma sociedade diversificada. Segundo Mantoan (2015), os lugares de convivência e aprendizado são diversos e a educação escolar deve ser entendida a partir da formação global do estudante, levando em consideração suas habilidades e qualidades, e de um ensino participativo, humanizado e receptivo.

Na prática, busca-se favorecer a aprendizagem de todos, sendo essencial que o professor observe tanto as características distintas presentes entre os estudantes como a pluralidade 
metodológica para desenvolver sua prática educativa. Lidar com tais diversidades, buscando a inclusão de todos, vem contribuir para a evolução da ação docente, pois tal realidade proporciona novos significados à prática. A inclusão exige ser (re)inventada a cada nova situação, sendo todos aprendizes nesse contexto (ORRÚ, 2017; CAPELLINE; RODRIGUES, 2009).

Para que um ambiente seja inclusivo é necessário desenvolver meios para que todos possam desenvolver o sentimento de pertencimento, havendo ou não deficiência. Assim, a pessoa com deficiência não deve simplesmente se ajustar ao ambiente que já existe (PACHECO, EGGERTSDÓTTIR; MARINÓSSON, 2007). Quando a inclusão é realizada de forma justa, propicia avanços na aprendizagem e promove qualidade de vida. Durante esse processo, o professor se torna mais reflexivo a partir de suas práticas, pois as adapta a partir do novo olhar sobre o processo de ensino e aprendizagem (BARBOSA-LIMA; CASTRO, 2012).

A inclusão requer mudanças na sociedade e no ambiente escolar, através da transformação de comportamento e atitudes, tornando possível a garantia do acesso e permanência do estudante na escola, além de respeitar as características intrínsecas de cada indivíduo. Essa concepção requer que sejam repensados currículos, didáticas, métodos avaliativos, capacitação do corpo escolar etc. (GLAT, 2018; CRUZ; GLAT, 2014; CAPELLINE; RODRIGUES, 2009).

A Lei Brasileira de Inclusão (BRASIL, 2015) lista seis tipos de barreiras que podem impedir que a pessoa com deficiência exerça sua autonomia como indivíduo, podendo ocorrer em ambiente públicos ou particulares. Essas barreiras podem ser urbanísticas, arquitetônicas, em meios de transporte, na comunicação e na informação, atitudinais e/ou tecnológicas. Dessa forma, é necessário que o ambiente seja propício para que pessoas com ou sem deficiência possam desenvolver atividades em sociedade.

Na sociedade contemporânea, o acesso ao conhecimento produzido ocorre quase que totalmente através de sistemas simbólicos em que o sentido da visão é priorizado, sendo a percepção do meio constituída através do uso de imagens e recursos audiovisuais (SARDELICH, 2006). A utilização desses recursos marca a formação educacional dos estudantes, evidenciando questões do ambiente social em que estão inseridos (MARTINS, 2010).

Dessa forma, estudantes com deficiência visual, por exemplo, apresentarão obstáculos significativos para assimilar significados que estejam atrelados a concepções visuais. É necessário que o professor busque meios de apresentar tais conteúdos de formas que permitam que os estudantes tenham vivências para sua formação como um todo, tendo meios que atuem como ferramentas que auxiliem a incorporar conceitos e conteúdos de outras formas (FOCHESATO; GUIMARÃES, 2017).

Assim, torna-se também necessário repensar e refletir a correlação entre a formação inicial de professores da Educação Básica e os recursos pedagógicos utilizados durante o exercício da docência (DARROZ; ROSA; GHIGGI, 2015, ROSA; DARROZ; MARCANTE, 2012), em especial do professor de Física. Houve, por exemplo, a criação da linha de pesquisa "Ensino de Ciências para alunos com Necessidades Educacionais Especiais", implementada no período de 2005 a 2011, na Universidade Estadual Paulista “Júlio de Mesquita Filho", em São Paulo, a partir 
da confecção de vários trabalhos desenvolvidos por pesquisadores ligados à temática de pesquisa (CAMARGO, 2014).

Segundo dados da Pesquisa Nacional de Saúde (BRASIL, 2019), em 2013 cerca de 3,6\% da população brasileira tinha deficiência visual, sendo que 3,3\% manifestaram a deficiência devido a alguma doença ou acidente e $0,4 \%$ nasceram com ela. A deficiência visual pode variar de perda visual leve a ausência total de visão (OMS, 2003). Segundo a Classificação Estatística Internacional de Doenças e Problemas Relacionados à Saúde (CID-10), é levada em consideração a acuidade visual no melhor olho para avaliar se o indivíduo é tido como deficiente visual. A inclusão de estudantes PAEE no ambiente escolar deve considerar também a acessibilidade arquitetônica, tecnológica e a comunicação entre estudantes e professores no processo de ensino e aprendizagem.

Em relação ao ensino de Física, diversos pesquisadores têm buscado desenvolver trabalhos relacionados ao ensino na perspectiva de estudantes com deficiência visual incluídos em turmas de ensino regular. O principal objetivo desses trabalhos tem sido contemplar aulas que proporcionem interações entre estudantes com e sem deficiência visual (VERASZTO et al., 2018; SILVA; CAMARGO, 2018; CORDOVA et al., 2017).

\section{Detalhamento das atividades}

O processo de inclusão de estudantes PAEE tem ganhado destaque, com a evidente necessidade de se entender como a formação inicial e/ou continuada pode contribuir para que o docente se sinta mais seguro e preparado, tanto em relação às suas inquietações e dúvidas quanto à sistematização de planejamento e desenvolvimento de atividades adaptadas. Nesse contexto, surge uma grande preocupação em relação ao processo de ensino de Ciências/Física para estudantes com deficiência visual, uma vez que o sentido da visão é priorizado durante as práticas de ensino.

Para a realização deste trabalho, optou-se por uma pesquisa bibliográfica na Plataforma SciELO, com o intuito de levantar e analisar o que se produziu em relação ao tema formação de professores e inclusão de estudantes PAEE, em especial deficientes visuais. Dadas as características desta plataforma, tendo em vista seus critérios de inserção de periódicos, podese inferir quanto à relevância e à representatividade de um levantamento efetuado em seu domínio (SHINTAKU et al., 2014).

Considerando a natureza da temática, que carrega múltiplos e distintos significados, optamos por uma abordagem qualitativa para a investigação. A pesquisa bibliográfica proporciona uma visão abrangente dos fenômenos almejados e um conhecimento mais aprofundado durante o desenvolvimento do tema, traçando uma linha histórica que permite melhor compreensão a respeito do objeto estudado e como vem sendo apresentado na literatura (GIL, 2017).

Para melhor delimitar a relevância do tema nos artigos publicados pela plataforma, o levantamento inicial foi subdivido em cinco outros levantamentos, com algumas variações das palavras-chave para, por fim, observar as publicações referentes ao processo de inclusão e ao 
ensino de Física. Assim, as palavras-chave utilizadas foram: inclusão, educação inclusiva, Educação Especial, necessidades educacionais especiais, formação de professores, ensino de Ciências, ensino de Física, formação de professores de Física, deficiência visual.

O levantamento de artigos na plataforma SCIELO foi realizado no primeiro semestre de 2019. Foram listados cinco conjuntos de palavras-chave para direcionar a pesquisa para artigos que contemplassem o ensino de Ciências/Física. Inicialmente, foram encontrados quarenta e seis artigos, excluindo os trabalhos que foram listados em mais de um levantamento, e apenas vinte e seis apresentavam relevância para este trabalho. Os vinte trabalhos que foram eliminados da análise estavam relacionados, em sua grande maioria, à área de Educação Física.

Para a análise dos dados, adotamos estratégias inspiradas na Análise de Conteúdo (AC), contemplando categorias prévias como: percepção da diversidade do ambiente escolar, aproximação entre o Ensino Superior e a Educação Básica e oferta de formação iniciada e/ou continuada. A utilização de categorias possibilita a realização de uma análise do que há em comum entre os elementos. Segundo Bardin (2011), a AC pode ser vista como uma composição de técnicas de análise das comunicações que visa alcançar através de procedimentos sistemáticos e objetivos de detalhamento do conteúdo de mensagens que possibilitem a compreensão de informações que estão associados a essas mensagens.

Este trabalho tem potencial para ser utilizado como ponto de partida para novas pesquisas dentro dessa temática, pois apresenta uma visão ampla e sistematizada das pesquisas desenvolvidas até este momento. Além disso, pode auxiliar na delimitação de novos temas, contribuindo para o desenvolvimento de estudos que preencham lacunas na literatura, promovendo reais contribuições para a área.

\section{Análise e discussão}

No primeiro levantamento foram utilizadas as palavras-chaves: inclusão, educação inclusiva, Educação Especial, necessidades educacionais especiais e formação de professores. Os oito artigos encontrados foram publicados entre 2009 e 2018, somente um não era relacionado à formação de professores e foi retirado da análise. A partir da leitura dos sete artigos selecionados, pôde-se perceber que o processo de inclusão e formação docente foram os principais temas abordados.

Observou-se nos trabalhos encontrados no primeiro levantamento, uma breve retrospectiva da história da Educação Especial, utilizando como referências marcos internacionais e a legislação brasileira, que buscam assegurar os direitos da pessoa com deficiência, além de apresentarem pesquisadores já consagrados como referência em seus trabalhos.

Ainda em relação aos trabalhos analisados no primeiro levantamento, pôde-se observar quatro que apresentaram como metodologia de análise de dados a Análise do Conteúdo (AC), enquanto os demais utilizaram metodologias diferentes e que não se repetiam entre si.

Os trabalhos ressaltam a importância da formação dos professores para que estes possam melhor desenvolver atividades que de fato promovam a inclusão dos estudantes na escola, e a 
necessidade de uma rede de apoio para compartilhar experiências entre os envolvidos. Dessa forma, o profissional teria melhor amparo, ainda que restem muitas dúvidas quanto à inclusão de estudantes PAEE em turmas de ensino regular.

A partir das palavras-chave utilizadas, observou-se que houve predominância de publicações na Revista Brasileira de Educação Especial com sete dos oito artigos obtidos nessa busca inicial. A revista Educar em Revista apresentou um trabalho dentro do primeiro levantamento.

No segundo levantamento foram utilizadas as palavras-chaves: inclusão, educação inclusiva, ensino de Ciências, necessidades educacionais especiais e formação de professores. Foram encontrados quatro artigos publicados entre 2010 e 2018. Houve a presença de um trabalho apresentado durante o primeiro levantamento realizado e, por esse motivo, não foi explicitado novamente. Dessa forma, o segundo levantamento foi realizado com três artigos.

O tema central dos trabalhos era a formação docente para a atuação na Educação Básica levando em consideração a presença de estudantes PAEE incluídos em turmas regulares de ensino. Um artigo do conjunto apresentou a questão das diversas abordagens do que vem ser inclusão, enquanto outro tratava de como os professores de Ensino Superior desenvolveram atividade com estudantes com deficiência visual. A metodologia mista foi a técnica de análise de dados predominante, presente em dois trabalhos, em que são empregadas simultaneamente análises quantitativas e qualitativas.

Nesse levantamento, as revistas que se destacaram foram: Educação e Pesquisa, Ensaio e Educação em Revista. Os trabalhos analisados apresentaram como foco a necessidade da formação dos graduandos sobre a importância de desenvolverem estudos acerca do que vem a ser a educação inclusiva e como melhor auxiliar durante a graduação. Dessa forma, quando se tornassem regentes de aulas, estariam mais capacitados e familiarizados à temática.

No terceiro levantamento foram utilizadas as palavras-chave: inclusão, educação inclusiva, ensino de Física, necessidades educacionais especiais e formação de professores. Foram encontrados três artigos publicados entre 2010 e 2018. Os trabalhos já haviam sido contemplados durante o segundo levantamento, não sendo analisados novamente.

No quarto levantamento foram utilizadas as palavras-chave: inclusão e formação de professores de Física. Foram encontrados vinte e quatro artigos publicados entre 2010 e 2018 , sendo que apenas três trabalhos contemplavam a temática relacionada à formação de professores de Física e ambos haviam sido contemplados nos levantamentos anteriores.

No quinto levantamento foram utilizadas as palavras-chave: deficiência visual, inclusão e ensino de Física. Foram encontrados quinze artigos publicados entre 2006 e 2018. Desses trabalhos, três não eram relacionados ao ensino de Física e um havia sido contemplado em outro levantamento. Logo, o quinto levantamento foi composto por onze trabalhos.

Durante a leitura dos artigos, destacaram-se como temas abordados pelos autores: processo de inclusão e formação docente. Os trabalhos foram desenvolvidos em instituições de Ensino Superior e de Ensino Médio. 
Através dos relatos apresentados nos artigos, evidenciamos que os autores destacam a importância e a necessidade de desenvolver pesquisas que tenham como objetivo proporcionar a inclusão de estudantes com deficiência visual nas aulas de Física. Buscando desenvolver meios para que licenciandos tenham maior contato com esses estudantes, foram propostas atividades dentro de disciplinas do curso de Física com o objetivo de auxiliar no planejamento didático, considerando a presença de alunos com deficiência visual em turmas regulares de ensino. Dessa forma, a expectativa era a de que o futuro docente construísse uma postura inclusiva e ativa durante o processo de ensino e aprendizagem, tendo um olhar para com o estudante com deficiência visual além de seu quadro, buscando desenvolver suas potencialidades.

A necessidade de uma comunicação mais estreita entre o professor regente de Física e o professor do AEE foi destacada como possibilidade para o desenvolvimento de atividades que contemplassem todos os estudantes da turma, independente de apresentar deficiência visual ou não. Em outro trabalho, os autores apresentam o aprendizado mediado como uma possibilidade de desenvolver atividades com esses estudantes, sendo utilizados os Ciclos de Aprendizagem (CA) como uma alternativa para estimular os estudantes na estruturação de um modelo conforme regras da pesquisa científica. Nessa abordagem o professor mantém-se presente, mas desempenha o papel de facilitador, devendo descrever, verbalmente, de forma sucinta e clara para seus estudantes, pois assim os esses podem acompanhar melhor as situações propostas com minimização das eventuais dificuldades.

Cinco artigos analisados foram escritos pelos mesmos autores, mas com olhares diferentes, em diversos tópicos relacionados ao ensino de Física. Outro ponto a ressaltar é a utilização da AC como metodologia de análise de dados em sete artigos e a Análise do Discurso em dois. Metade dos trabalhos analisados foi desenvolvida por pesquisadores lotados na Universidade Estadual Paulista (UNESP).

A partir da análise dos artigos selecionados foi possível organizar as categorias: foco das pesquisas, ano de publicação, metodologia de análise de dados, revistas de publicação e instituições de vínculo dos autores.

Quanto ao foco, os artigos abordam os desafios do processo de inclusão de estudantes PAEE em turmas regulares, do Ensino Infantil ao Ensino Superior, e a importância da formação de professores. Uma característica ponderada foi a abordagem de caráter técnico ou informativo da temática nos cursos de formação, o que representa uma séria dificuldade para planejar a atuação em contextos reais vivenciados na Educação Básica. Desta forma, o futuro professor apresentará dificuldades durante sua prática e em pensar a flexibilização curricular para atender esse estudante.

No Gráfico 1, pode-se observar que o período de publicações de artigos relacionados às temáticas foi de 2006 a 2018, sendo que 2010 representou o ano mais produtivo. Nesse gráfico, foram listados todos os artigos utilizados nos cinco levantamentos. 
Gráfico 1: Quantitativo de artigos publicados por ano.

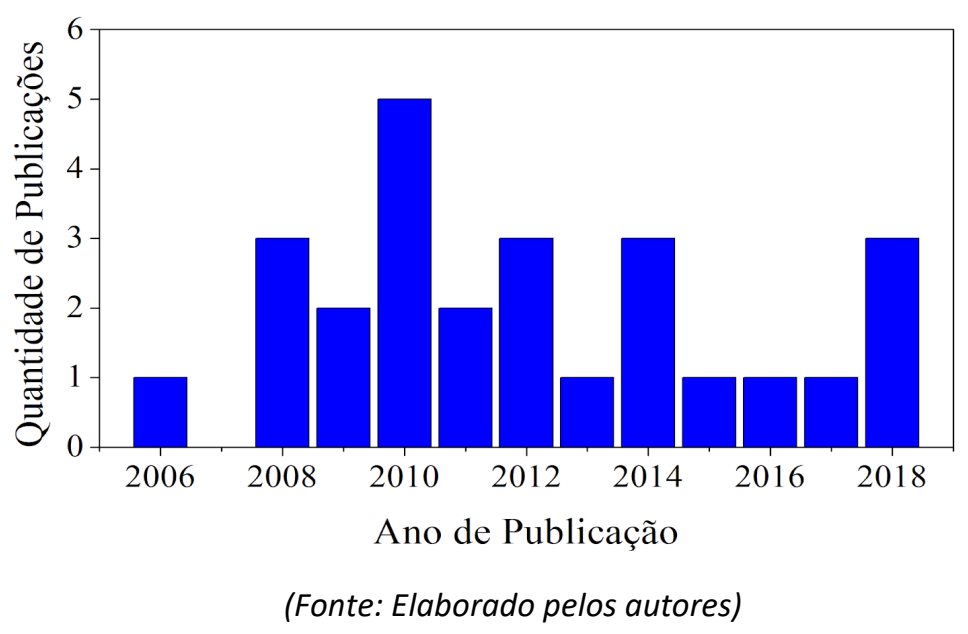

Em relação às publicações relacionadas ao quinto levantamento, voltado para a inclusão de alunos com deficiência visual no ensino de Física, o Gráfico 2 mostra que nos anos de 2008 e 2014 houve maior número de publicações sobre inclusão e ensino de Física, considerando também o artigo que havia sido contemplado em outro levantamento. Foram publicados três artigos em cada ano, representando $50 \%$ do total dos trabalhos listados.

Gráfico 2: Quantitativo de publicações e ano de publicação.

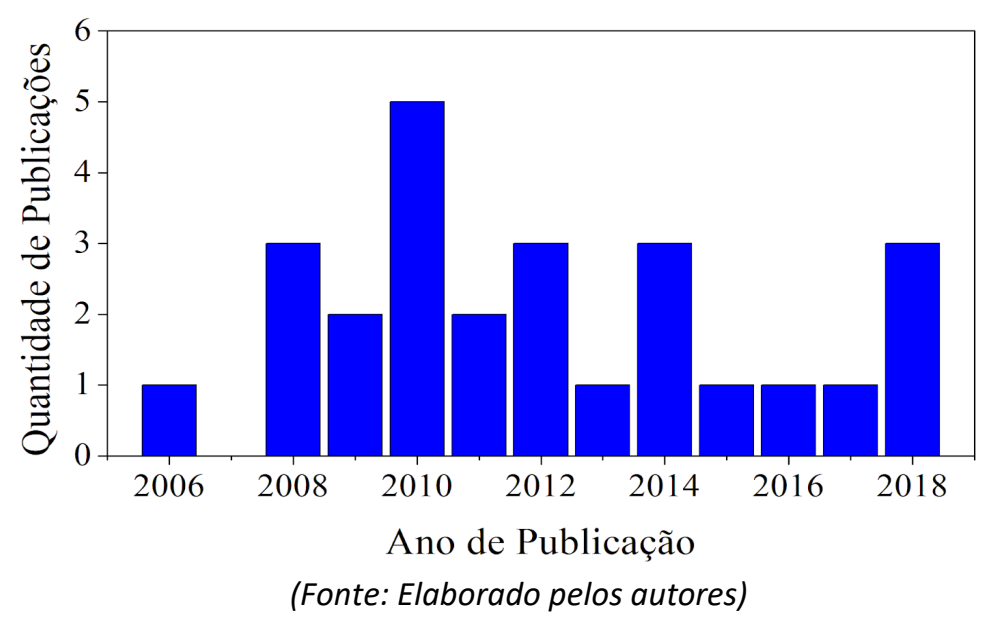

Em relação às metodologias de análise de dados, percebe-se, pelo Gráfico 3, que a metodologia mais utilizada foi a Análise de Conteúdo, presente em $55 \%$ dos artigos, ou seja, em 14 trabalhos. Em menor proporção, seguem-se a Análise do Discurso e a metodologia "mista", com $15 \%$ cada. A metodologia "mista" combina tanto a abordagem quantitativa como a qualitativa, sem indicar predomínio de uma ou outra. Apesar disto, em algum momento durante a análise, uma das abordagens pode se sobrepor (CRESWELL, 2007). Segundo Paranhos et al. (2006), o pesquisador deve ter o tema e os objetivos do trabalho bem definidos, pois, ao utilizar essa metodologia "mista", corre o risco de ter vários recortes da pesquisa, o que pode representar uma postura ingênua ou pouco criteriosa. 
Gráfico 3: Metodologias de análise de dados utilizadas nos artigos analisados.

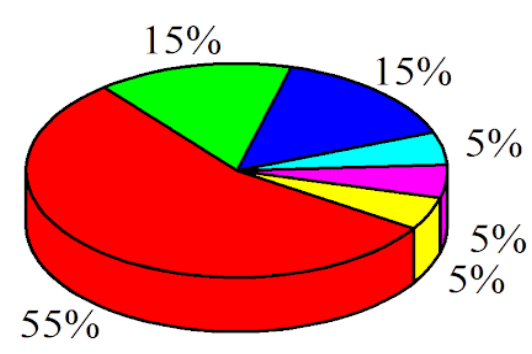

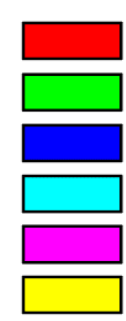

Análise de Conteúdo

Análise do Discurso

Metodologia Mista

Análise de Entrevistas e Áudios

Análise de Questionários

Análise Quantitativa Interpretativa

(Fonte: Elaborado pelos autores)

Vale ressaltar que em uma parcela significativa dos trabalhos, cerca de $15 \%$, a metodologia de análise de dados não foi explicitada. Segundo Praça (2015), a análise de dados deve remeter às estratégias/técnicas empregadas que, ao serem examinadas, devem elucidar se o percurso metodológico logrou êxito. Assim, essa ausência na explicitação implica no risco de uma abordagem superficial da temática de pesquisa.

Em relação ao quantitativo de artigos publicados, a Revista Brasileira de Educação Especial apresentou o maior número de publicações, representando $29 \%$ dos trabalhos analisados, seguida pelas revistas Ensaio e Revista Brasileira de Ensino de Física, com 17\%. As demais revistas analisadas foram: Ciência e Educação, com 13\% dos artigos analisados, Educação e Pesquisa, Educação em Revista, Avaliação, Educar em Revista e Revista Electrónica de Investigación en Educación en Ciencias, cada uma apresentando 4\% dos trabalhos.

No quinto levantamento, constatou-se que as revistas Ensaio, Revista Brasileira de Ensino de Física e Ciência \& Educação apresentaram maior número de publicações dentro do tema inclusão e ensino de Física, cada uma com três artigos, representando $75 \%$ do total de trabalhos analisados. As revistas Avaliação, Revista Brasileira de Educação Especial e Revista Electrónica de Investigación en Educación en Ciencias apresentaram um artigo cada.

Além disso, constatou-se que cerca de $80 \%$ dessas revistas possuem sede na região sudeste, $10 \%$ na região sul e $10 \%$ fora do Brasil. Ainda, pode-se destacar que 21 artigos foram escritos por pesquisadores da região sudeste, representando em torno de $81 \%$ dos trabalhos, seguida pela região sul, com aproximadamente $8 \%$, e regiões centro-oeste e nordeste, com $2,6 \%$ cada. Esses dados corroboram os resultados da pesquisa realizada (Pesquisa realizada pela Research in Brasil: A report for CAPES by A Clarivate Analytics company) pelo Web of Science Group (2019), apontando que 60\% da produção científica brasileira é realizada em 15 universidades públicas localizadas na região sudeste. Certamente que essa representatividade implica em desafios ao avanço e à qualificação do processo de inclusão, uma vez que os pesquisadores estão concentrados em alguns poucos grandes centros de pesquisa, os quais estão centrados nas universidades. 
Cumpre refletir que o aprimoramento dos processos de ensino-aprendizagem requer pesquisa, especialmente e mesmo considerando as limitações impostas pelo cenário real, pelo professor diretamente envolvido no contexto escolar (MARTINS; VARANI, 2012).

\section{Considerações}

Os trabalhos analisados ressaltam a importância do processo de inclusão de estudantes PAEE em turmas regulares, do Ensino Infantil ao Superior, a reivindicação manifesta pelos professores por uma melhor formação inicial e/ou continuada e a necessidade de uma rede de apoio pedagógico. No que se refere ao ensino de Física, verificou-se que o tema gera tensão na comunidade acadêmica e há grande preocupação em promover uma formação adequada aos licenciandos no que tange à inclusão dos estudantes PAAE e à implementação de propostas para melhor desenvolver atividades integradoras entre estudantes com e sem deficiência.

Com isso, caracterizou-se um grande desejo de possibilitar ao futuro docente a construção de uma postura inclusiva e ativa durante o processo de ensino-aprendizagem, percebendo o estudante PAEE além de seu quadro, buscando desenvolver suas potencialidades. Entretanto, também ficou evidente que a formação inicial apresenta contextos adversos e que há grandes dificuldades em renovar a cultura escolar em função das particularidades dos estudantes de inclusão.

Apesar dessa inclusão ser prevista em lei, ainda faltam políticas públicas que incentivem a habilitação dos profissionais de educação tanto durante a formação inicial quanto na formação continuada. Necessidades formativas urgentes, pois, o professor, na maioria das vezes, ressente-se de condições para enfrentar os desafios referentes ao processo de ensino e aprendizagem desses estudantes.

O desenvolvimento de pesquisas que abordam essa temática tem apresentado um aumento gradual, principalmente a partir de 2008, mas ainda é necessário ampliar as pesquisas na área de ensino de Física e publicações em periódicos. Observou-se que o principal públicoalvo de pesquisas relacionadas à inclusão e ensino de Física é o de deficientes visuais. Seria interessante verificar como é realizado o processo de inclusão e ensino de Física para outros públicos, como surdos e autistas.

Torna-se importante buscar promover a inclusão real dos estudantes PAAE em turmas regulares de ensino. A inclusão ocorre quando há a participação desses estudantes de forma ativa na escola, tendo suas particularidades respeitadas, a partir da preparação de materiais possíveis de serem utilizados por estudantes que apresentem algum quadro de deficiência ou não. É necessário que o processo de inclusão ocorra de forma mais efetiva e não de forma velada, o que representaria o processo de integração em que o indivíduo não é visto como parte integrante da sociedade ou tem suas particularidades respeitadas. 


\section{Referências}

ANTUNES, Helenise Sangoi; RECH, Andréia Jaqueline Devalle; AVILA, Cínthia Cardona de. C. Educação inclusiva e formação de professores: desafios e perspectivas a partir do Pacto Nacional pela Alfabetização na Idade Certa. Práxis Educativa, v. 11, n. 1, p. 171-198, 2016.

BARBOSA-LIMA, Maria da Conceição; CASTRO, Giselle Faur de. Formação inicial de professores de física: a questão da inclusão de alunos com deficiências visuais no ensino regular. Ciência \& Educação, vol. 18, n. 1, p. 81-98, 2012.

BARDIN, Laurence. Análise de conteúdo. São Paulo: Edições 70, 2011.

BATISTA, Heloisa Fernanda Francisco. A inclusão de estudantes com deficiências na educação básica: percurso e desafios a partir de um estudo de caso. Trabalho de Conclusão de Curso. Universidade Federal de Uberlândia. 2017.

BRASIL. Instituto Nacional de Estudos Educacionais Anísio Teixeira. Sinopse Estatística da Educação Básica 2019. Brasília: Inep, 2020. Disponível em: <http://portalinep.gov.br/sinopsesestatisticas-de-educacao-basica>. Acesso em: 13 dez. 2020.

BRASIL. Política Nacional de Educação Especial na perspectiva da Educação Inclusiva. Brasília, 19p. 2008. Disponível em <http://portal.mec.gov.br/arquivos/pdf/politicaeducespecial.pdf> Acesso em 04 out. 2020.

BRASIL. Lei 13.146, de 06 de julho de 2015. Institui a Lei Brasileira de Inclusão da Pessoa com Deficiência (Estatuto da Pessoa com Deficiência). Diário Oficial da União, Brasília, DF, 2015. Disponível em <http://www.planalto.gov.br/CCIVIL 03/ Ato2015-2018/2015/Lei/L13146.htm> Acesso em: 12 jan. 2021.

BRASIL. Lei 13.005, de 25 de junho de 2014. Aprova o Plano Nacional de Educação - PNE e dá outras providências. Diário Oficial da União, Brasília, DF, 2014. Disponível em $<$ http://pne.mec.gov.br/18-planos-subnacionais-de-educacao/543-plano-nacional-deeducacao-lei-n-13-005-2014> Acesso em: 12 jan. 2021.

BRASIL. Lei 10.172, de 09 de janeiro de 2001. Aprova o Plano Nacional de Educação e dá outras providências. Diário Oficial da União, Brasília, DF, 2001. Disponível em <https://www.planalto.gov.br/ccivil 03/leis/leis 2001/l10172.htm> Acesso em: 13 jan. 2021.

BRASIL. Lei de Diretrizes e Bases da Educação Nacional. Estabelece as diretrizes e bases da educação nacional. Diário Oficial da União. Brasília, DF, 1996. Disponível em $<$ https://www2.senado.leg.br/bdsf/bitstream/handle/id/70320/65.pdf> Acesso em: 13 jan. 2021.

BRASIL. Lei no 8.069, de 13 de julho de 1990. Dispõe sobre o Estatuto da Criança e do Adolescente e dá outras providências. Diário Oficial da União. Brasília, DF, 1990. Disponível em <https://www.planalto.gov.br/ccivil 03/leis/L8069.htm> Acesso em: 13 jan. 2021. 
CAMARGO, Eder Pires de, NARDI, Roberto. O emprego de linguagens acessíveis para alunos com deficiência visual em aulas de Óptica. Revista Brasileira de Educação Especial, 14(3), p. 405-426, 2008.

CAMARGO, Eder Pires de. Processo de consolidação da implantação de linha de pesquisa relacionada ao ensino de ciências para alunos com necessidades educacionais especiais. II Congresso Nacional de Formação de Professores; XII Congresso Estadual Paulista sobre Formação de Educadores, p. 8886-8897, 2014. Disponível em: $<$ https://repositorio.unesp.br/bitstream/handle/11449/141852/ISSN2357-7819-2014-88868897.pdf?sequence=1\&isAllowed $=\mathrm{y}>$ Acesso em 18 jan. 2021.

CAMARGO, Eder Pires de. A comunicação como barreira à inclusão de alunos com deficiência visual em aulas de mecânica. Ciência \& Educação, v. 16, n. 1, p. 258-275, 2010.

CAPELLINI, Vera Lucia Messias Fialho; RODRIGUES, Olga Maria Piazentin Rolim. Concepções de professores acerca dos fatores que dificultam o processo da educação inclusiva. Educação, Porto Alegre, v.32, n.3, p.355-364, 2009.

CARMO, Bruno Cleiton Macedo et al. Políticas públicas educacionais e formação de professores: convergências e distanciamentos na área de Educação Especial. Revista Educação Especial, v. 32, p. 113, 2019.

CORDOVA, Hercílio. P. et al. Audiotermômetro: um termômetro para a inclusão de estudantes com deficiência visual. Revista Brasileira de Ensino de Física, v. 40, n. 2, 2018.

CRESWELL, John W. Projeto de pesquisa: métodos qualitativo, quantitativo e misto. Porto Alegre: ARTMED, 2010.

CRUZ, Gilmar de Carvalho; GLAT, Rosana. Educação inclusiva: desafio, descuido e responsabilidade de cursos de licenciatura. Educar em Revista, Curitiba, Brasil, n. 52, p. 257273, 2014.

DARROZ, Luiz Marcelo. ROSA, Cleci Werner, GHIGGI, Caroline Maria. Método tradicional x aprendizagem significativa: investigação na ação dos professores de Física. Aprendizagem Significativa em Revista, v. 5(1), p. 70-8, 2015.

FARIA, Karla Tomaz et al. Atitudes e práticas pedagógicas de inclusão para o aluno com autismo. Revista Educação Especial, p. 353-370, 2018.

FOCHESATO, Raquel de Abreu, GUIMARÃES, Orliney Maciel. Tendências de pesquisas internacionais sobre o ensino de ciências para deficientes visuais: foco nos materiais didático para o ensino de química. Revista Debates em Ensino de Química, v. 3, p. 47-68, 2017.

FRANZIN; Rozelaine de Fátima; ZWAN, Liciara Daiane; CALLEGARO, Morgana. Educação inclusiva de surdos e o contexto tecnológico na Educação Básica: uma experiência do projeto PICMEL. Ensino de Ciências e Tecnologia em Revista, v. 10, n. 1, p. 09-24, 2020.

GIL, Antonio Carlos. Como elaborar projetos de pesquisa. São Paulo: Atlas, 2017.

GLAT, Rosana. Desconstruindo representações sociais: por uma cultura de colaboração para inclusão escolar. Revista Brasileira de Educação Especial, v.24, Edição Especial, p.9-20, 2018. 
GOULART, F. Inclusão de verdade. 2014. Disponível em: $<$ http://www.filosofiahoje.com/2014/01/inclusao-social-de-verdade.html> Acesso em 01 out 2020

MANTOAN, Maria Tereza Égler. Inclusão escolar: O que é? Por quê? Como fazer? Ed. Summus, 2015.

MARTINS, Marcos Francisco; VARANI, Adriana. Professor e pesquisador: considerações sobre a problemática relação entre ensino e pesquisa. Revista Diálogo Educacional, v. 12, n. 37, p. 647680, 2012.

MARTINS, Raimundo. Hipervisualização e territorialização: Questões da Cultura Visual. Educação \& Linguagem, v. 13, p. 19-31, 2011.

OMS. Classificação Estatística Internacional de Doenças e Problemas Relacionadas à Saúde. São Paulo: EDUSP, 2003.

ONU. Declaração de Salamanca sobre princípios, política e práticas na área das necessidades educativas especiais Salamanca. ONU, 1994.

ONU. Declaração Universal dos Direitos Humanos. ONU, 1949.

ORRÚ, Silvia Ester. Possibilidades de (re)inventar a inclusão para os aprendizes do século XXI: contribuições da filosofia da diferença de Gilles Deleuze. Educação e Filosofia, v. 31, n. 62, p. 1127-1158, 2017.

PACHECO, José; EGGERTSDÓTTIR, Rosa; MARINÓSSON, Gretar L. Caminhos para a inclusão: um guia para o aprimoramento da equipe escolar. Porto Alegre: Artmed, 2007.

PARANHOS, Ranulfo et al. Uma introdução aos métodos mistos. Sociologias, Porto Alegre, v. 18, n. 42, p. 384-411, 2016.

PRAÇA, Fabíola Silva Garcia. Metodologia da pesquisa científica: organização estrutural e os desafios para redigir o trabalho de conclusão. Revista Eletrônica Diálogos Acadêmicos, v. 08, n. 1, p. 72-87, 2015.

ROCHA, Artur Batista de Oliveira. O papel do professor na educação inclusiva. Ensaios Pedagógicos, São Carlos, v. 7, n. 2, 2017.

ROSA, Cleci Werner da; DARROZ, Luiz Marcelo; MARCANTE, Tomas Edson. A avaliação no ensino de Física: práticas e concepções dos professores. Revista Electrónica de Investigación en Educación en Ciencias, 7(2), p. 41-53, 2012.

SANTOS, Tatiana dos; BARBOSA, Regiane da Silva. Educação Inclusiva. Londrina: Editora e Distribuidora Educacional S.A., 2016.

SARDELICH, Maria Emília. Leitura de imagens e cultura visual: desenredando conceitos para a prática educativa. Educar em Revista, n. 27, p. 203-219, 2006.

SASSAKI, Romeu Kazumi. Inclusão: construindo uma sociedade para todos. Rio de Janeiro: WVA editora, 1999. 
SHINTAKU, Milton; BRITO, Ronnie F. DE; CARVALHO NETO, Sílvio. A avaliação dos portais de revistas brasileiros implementados com o SEER/OJS por meio do levantamento da indexação pelo Latindex e SciELO. Informação \& Sociedade: Estudos, v. 24, n. 2, 2014.

SILVA NETO, Antenor de Oliveira et al. Educação inclusiva: uma escola para todos. Revista Educação Especial, v. 31, n. 60, p. 81-92, mar. 2018.

SILVA, Ana Paula Mesquita da; ARRUDA, Aparecida Luvizotto Medina Martins. O papel do professor diante da inclusão escolar. Saberes da Educação, São Roque, v. 5, n. 1, p. 1-29, 2014. SILVA, Maria Odete Emygdio da. Da exclusão à inclusão: concepções e práticas. Revista Lusófona de Educação, n. 13, p. 135-153, 2009.

TORRES, Josiane Pereira; MENDES, Enicéia Gonçalves. Atitudes Sociais e Formação Inicial de Professores para a Educação Especial. Revista Educação Especial, v. 25, p. 765-780, 2019a.

TORRES, Josiane Pereira; MENDES, Enicéia Gonçalves. Formação de professores de ciências exatas numa perspectiva inclusiva. Revista Insignare Scientia - RIS, v. 1, n. 3, 17 fev. 2019b.

UNESCO. Declaração Mundial sobre Educação para Todos: satisfação das necessidades básicas de aprendizagem. Jomtien, 1990.

VERASZTO, Estéfano Vizconde et al. Conceitualização em ciências por cegos congênitos: um estudo com professores e alunos do ensino médio regular. Revista Electrónica de Enseñanza de las Ciencias, v. 17, n. 13, p. 540-563, 2018.

VOOS, Ivani Cristina; FERREIRA, Gabriela Kaiana. Acessibilidade para estudantes cegos e baixa visão: análise dos objetos educacionais digitais de física. Revista Educação Especial, v. 31, n. 60, p. 21-34, 2018. 